\title{
Configurações
}

Revista de sociologia

\section{Interacciones entre Derecho y Literatura: El artículo 57 de la Constitución de la República del Ecuador}

Interactions between Law and Literature: Article 57 of the Constitution of the Republic of Ecuador

Interactions entre le Droit et la Littérature : l'article 57 de la Constitution de l'Équateur

Rina Pazos

\section{OpenEdition}

\section{Journals}

Electronic version

URL: http://journals.openedition.org/configuracoes/5987

DOI: $10.4000 /$ configuracoes.5987

ISSN: 2182-7419

Publisher

Centro de Investigação em Ciências Sociais

Printed version

Number of pages: 117-131

ISSN: 1646-5075

\section{Electronic reference}

Rina Pazos, «Interacciones entre Derecho y Literatura: El artículo 57 de la Constitución de la

República del Ecuador », Configurações [Online], 22 | 2018, Online since 21 December 2018, connection on 19 April 2019. URL : http://journals.openedition.org/configuracoes/5987 ; DOI : 10.4000/ configuracoes.5987 
Pazos, Rina - Interacciones entre Derecho y Literatura: El artículo 57 de la Constitución de la República del Ecuador . Configurações, vol. 22, 2018, pp. 117-131.

\title{
Interacciones entre Derecho y Literatura: El artículo 57 de la Constitución de la República del Ecuador
}

RINA PAZOS*

Universidad Tecnológica Equinoccial, Universidade do Minho

\begin{abstract}
Resumen
Este artículo intenta aproximarse a las interacciones entre las disciplinas del Derecho y la Literatura que se han venido estudiando por el denominado movimiento de Law and Literature desde hace casi cinco décadas. Para ilustrar algunos puntos de encuentro entre estas dos disciplinas se pondrá como ejemplo el artículo 57 de la Constitución de la República del Ecuador que consagra los derechos colectivos de comunas, comunidades, pueblos y nacionalidades indígenas, y cuyo texto ha sido parcialmente utilizado por artistas ecuatorianos para crear una nueva obra audiovisual.
\end{abstract}

Palabras-claves: derecho, literatura, arte audiovisual, pueblos indígenas.

\begin{abstract}
Interactions between Law and Literature: Article 57 of the Constitution of the Republic of Ecuador

This article is an approximation to the interactions between the subjects of Law and Literature studied by the denominated Law and Literature movement for almost five decades. To illustrate some of the points of encounter between these two subjects, article 57 of the Constitution of the Republic of Ecuador, which consecrates the collective rights of indigenous peoples and nationalities, has been partially used by Ecuadorian artists to create a new audiovisual work.
\end{abstract}

Keywords: law, literature, audiovisual art, indigenous peoples.

\footnotetext{
Resumo

Interactions entre le Droit et la Littérature : l'article 57 de la Constitution de l'Équateur

Cet article est une approche des interactions entre les disciplines de Droit et de Littérature étudiées par ledit mouvement Law and Literature depuis presque cinquante

*E-mail: Rinapazos986@hotmail.com
} 
ans. Pour illustrer certains points de rencontre entre ces deux disciplines, nous citons en exemple l'article 57 de la Constitution de la République de l'Équateur qui consacre les droits collectifs des peuples et des nationalités indigènes et dont le texte est partiellement utilisé par des artistes équatoriens pour créer une nouvelle œuvre audiovisuelle.

Mots-clés: droit, littérature, art audiovisuel, peuples indigènes.

\section{Introducción}

Las relaciones entre el Derecho y la Literatura no son siempre evidentes. Es necesario un esfuerzo por identificar los puntos en los que se conectan y las maneras en las que se relacionan. El movimiento que inició estos estudios, por haber nacido en el ambiente en el que impera la tradición del common law, se enfoca más en las decisiones judiciales; sin embargo, también podrían existir relaciones entre estas dos disciplinas en la creación normativa al incidir de manera determinante las concepciones de justicia de los actores jurídico-políticos que construyen ex ante los sistemas jurídicos del civil law.

A menudo, la Literatura nos acerca a los elementos de la cultura que muestran el valor de justicia que la sociedad mantiene en un determinado momento histórico; así también lo hace el Derecho. Específicamente como narrativa, este nos aproxima a los aspectos de la cultura en cada momento histórico, permite identificar a qué concentración de poder responde el Derecho, los valores subyacentes en la narrativa y los agentes, principios y valores en contradicción.

La intención de este ensayo es procurar una reflexión sobre la interacción entre el Derecho y Literatura -cultura- en la norma, tanto desde la potencial influencia de la Literatura en la producción normativa, como en la norma comprendida como una forma de Literatura, así como en sus interacciones con la cultura popular. Metodológicamente, se parte de la incidencia de la Literatura en el Derecho planteada por Kieran Dolin, quien considera que, a través del discurso literario, se permite a los grupos marginados lograr una presencia en el debate público imposibilitada anteriormente (Porsdam, 2007: 132); desde esta perspectiva se analiza el potencial de la literatura para influir en la creación del derecho que, en la tradición del civil law se evidencia principalmente en la expedición de normas jurídicas formales. En este marco, se busca identificar posibles incidencias de la literatura en la creación de normas jurídicas en el Ecuador, específicamente en el artículo 57 de la Constitución de la República del Ecuador, el que reconoce derechos a los pueblos originarios no contactados de la selva amazónica en el Ecuador. Como ejemplo se identifica el contenido literario de la obra Cumandá del escritor ecuatoriano Juan León Mera, así como el contenido de los debates en la última Asamblea Constituyente del Ecuador, sobre los derechos colectivos de comunas, comunidades, pueblos y nacionalidades, que aluden a pasajes de obras literarias de 
autores ecuatorianos. Posteriormente, y como aspecto central del artículo, con fundamento en el modelo estético de interacción entre derecho y literatura expuesto por Botero (2008: 7), se analiza el contenido literario del ya citado artículo 57 desde una perspectiva artística, al haber sido su texto utilizado por artistas ecuatorianos como narrativa multimedia.

En la primera parte, se recorrerá brevemente por las ideas principales del movimiento del Derecho y Literatura. En la segunda parte, se intentará identificar las posibles influencias literarias del contenido del artículo 57 de la Constitución de la República y como el artículo en sí mismo se transmuta al mundo del arte audiovisual a través de la intervención de los artistas Miguel y Alex Alvear, así se reflexionará sobre el contenido del artículo en mención como narrativa del Derecho.

\section{El movimiento del Derecho y la Literatura}

De manera cada vez más frecuente, se observa que la interdisciplinariedad se identifica como un enfoque que permite construir el conocimiento de manera más integral y real, constituyéndose en una herramienta más eficaz para una academia más vinculada con su entorno y los problemas que existen en la sociedad. En ese marco en el que la definición del Derecho no tiene una respuesta única, sino que se mantiene en movimiento continuo, es que ha sido posible la aproximación a este desde otras disciplinas. La interacción de otras áreas del saber humano con el derecho permitiría un enriquecimiento en la reflexión, debate y construcción del conocimiento y la práctica jurídica.

El giro lingüístico en la filosofía que emergió a finales del siglo XIX y se profundizó en el siglo XX, tanto en la tradición filosófica alemana con Heidegger, Gadamer, Habermas como en la anglo - americana a través de los trabajos de Frege, Russell y Wittgenstein (Aguiar e Silva, 2008: 4-5), generó terreno fertil para pensar en las intersecciones entre la literatura y el derecho como un campo de estudio. Principalmente en Estados Unidos a finales de los años setenta del siglo XX esto acontenció con exponentes como Kieran Dolin, James Boyd White entre otros, y en una posible nueva concepción del derecho como literatura por ser el lenguaje su contenedor.

Aguiar e Silva (2008: 54-56) sintetiza dos clasificaciones de los estudios sobre Derecho y Literatura. La primera con dos vertientes: 1) Derecho en la Literatura que se centra en la perspectiva jurídica de las obras literarias y 2) Derecho como literatura que se enfoca en la caracterización del discurso jurídico como discurso lingüistico y literario. La segunda clasificación es la realizada por Robin West con cuatro ramas propias: 1) La construcción del ideal de jurista literato, 2) El proyecto crítico más apegado a la vertiente de estudios del Derecho en la Literatura, 3) La interpretación jurídica de los textos de autoridad jurídica, apegado a la vertiente de estudios de Derecho como Literatura; y, 
4) La del análisis, explicación y expansión de la voz narrativa del Derecho en el pensamiento y la enseñanza jurídica.

La narrativa de la literatura también puede incidir en el Derecho, principalmente en las decisiones judiciales, esta es una de las perspectivas más frecuentes que se identifica en el trabajo del movimiento Law and Literature. Así por ejemplo, en la revisión del texto de Kieran Dolin, Critical Introduction to Law and Literature, se señala que la literatura y el discurso literario permiten a los grupos marginados lograr una presencia imposibilitada previamente (Porsdam, 2007: 132) o la tesis de Martha Nussbaum sobre la humanización del derecho por medio de un discurso público construido desde la literatura (Botero, 2008: 2). Adicionalmente, Burke (2015: 63) señala que nunca podemos ser espectadores indiferentes de lo que los otros puedan hacer o sufrir; adjudica a las artes el poder de transportarnos a situaciones ficticias y hacernos sentir con intensidad la pasión de la simpatía que, a través de una especie de sustitución, nos coloca en el lugar de la otra persona, con lo cual sentimos una muy parecida afectación a la que el otro está sufriendo.

Sin embargo, autores como Richard Delgado y Jean Stefancic (1991: 19341955 ) ponen en duda la eficacia y oportunidad de la incidencia de la gran literatura en las decisiones judiciales, sin que esto signifique que nieguen el potencial del campo para lograr paulatinamente una mayor sensibilización en los operadores del mundo jurídico que apunte a la construcción de una sociedad más justa. Delgado y Stefancic abordan casos reales resueltos en las cortes estadounidenses desde finales del siglo XIX, que se relacionan con grupos marginados como los afrodescendientes, indígenas, homosexuales, mujeres, entre otros. Según los autores, los decisores de esos casos - hombres blancos - no fueron influenciados por las contra narrativas existentes que hubieran ayudado a no cometer errores morales fuertemente condenados en la actualidad; de tal manera señalan que, aunque los decisores hubieran contado con el repertorio literario de esas contranarrativas, las posibilidades de simpatizar con esos otros era reducida.

Por otro lado, Botero (2008: 4-7) propone una taxonomía de las relaciones derecho - literatura a través de los modelos: retórico, expositivo, metodológico, analítico, jurídico y estético. No es la intención de este trabajo profundizar en cada uno de ellos, sin embargo para brindar un contexto a la segunda parte se ha considerado pertinente detenernos en los modelos expositivo y estético. El autor considera que el modelo expositivo implica una función instrumental de la obra literaria a través del cual se usan las situaciones explicitadas en la obra para ilustrar los argumentos sobre un tema o justificar una propuesta en el mundo jurídico; mientras que, el modelo estético, más cercano a la clasificación del Derecho como Literatura, toma como elemento principal el discurso júridico como texto literario, entre ellos las normas, definiciones o declaraciones contenidas en los instrumentos jurídicos. No se trata de la incorporación de 
elementos de las obras literarias para adornar el derecho ni tampoco se remite a estas para explicarse. La mirada estética, a través de la obra de arte que sería el propio derecho, intenta poner de manifiesto el puente entre literatura y derecho que, además de impactar en el juicio estético de las personas, expone el discurso que contiene. Las palabras -aún con sus limitaciones- por lo que representan, la imagen que evocan y la forma en la que se pueden combinar, tienen el poder de sensibilizarnos, conmovernos, entristecernos y en general provocarnos intensas emociones (Burke, 2015: 190-204). Este efecto podría ayudar a disminuir las barreras entre el mundo social y el mundo jurídico históricamente amurallado por su metalenguaje, reputada racionalidad abstracta, ritos y costumbres que dificultan la permeabilidad en el diálogo entre los expertos y legos y que, de manera subyacente, remite a los problemas de la democracia y la justicia. La finalidad de buscar una mayor permeabilidad es, en palabras de Dolin, citado por Porsdam (2007: 132) "ethics and aesthetics become active partners with politics in creating the normative basis for a just society" (ética y estética se tornan socios activos con la política en la creación de una base normativa para una sociedad justa).

Podría ser difícil imaginar como el estilo y la disposición de la lógica deóntica del texto normativo jurídico puede ser apreciado estéticamente considerando que la función más relevante que se le ha adjudicado a la norma es dar una solución a un caso (Alchourrón \& Bulygin, 1987); sin embargo, Botero (2008: 1) destaca la virtud estética de definiciones y normas del ordenamiento jurídico colombiano como el artículo 719 del Código Civil ${ }^{1}$ y el artículo 5 de la Sección Segunda, Título Primero de la Constitución Antioqueña de $1812^{2}$, y así existirán muchas otras normas jurídicas que por la forma en la que están escritas mantienen valor estético aunque no haya existido una acción deliberada de sus autores por lograr este efecto.

\section{El artículo 57 de la Constitución de la República del Ecuador como narrativa en el Derecho}

Quizás debido a que el campo de estudio de Derecho y Literatura emergió en la academia estadounidense, con la tradición del anglosajónica este tiende a enfatizar las relaciones entre las dos disciplinas en el ámbito del ejercicio jurisdiccional; esto es, en la forma en como las decisiones judiciales pueden remitirse

\footnotetext{
1 "Se llama aluvión el aumento que recibe la ribera de un río o lago por el lento e imperceptible retiro de las aguas".

2 "Ningún hombre, ninguna corporación o asociación de hombres tiene algún título para obtener ventajas, o particulares y exclusivos privilegios, distintos de los que goza la comunidad sino es aquel que se deriva de la consideración que le den sus virtudes, sus talentos, y los servicios que haga, o haya hecho al público. Y no siendo este título por su naturaleza hereditario, ni transmisible a los hijos, descendientes, o consanguíneos, la idea de un hombre que nazca Rey, Magistrado, Legislador, o Juez es absurda y contraria a la naturaleza".
} 
a las obras literarias o como los jueces pueden encontrar en ellas una nueva perspectiva del mundo, de los sujetos o desarrollar la inteligencia creativa para lograr un desarrollo del derecho a través de sus sentencias más apegado al ideal de justicia que las sociedades aspiran en los diferentes momentos históricos. En la tradición civilística a la que pertenece América Latina, los textos escritos normativos mantienen su centralidad en lo que se comprende como Derecho. En ese marco, cabe intentar una aproximación a las relaciones entre derecho y literatura en el texto de la norma a través del siguiente ejemplo.

El Ecuador expidió su actual Constitución hace casi 10 años, en el $2008^{3}$. Los principios y valores que la impulsaron muestran un cambio de paradigma sobre la concepción del Estado y la sociedad ecuatoriana. Entre algunos puntos que merecen visibilidad para este trabajo está la declaración del Estado de derechos y justicia, unitario, intercultural y plurinacional ${ }^{4}$. Las implicaciones de esta declaración resultan retadoras para un país en desarrollo con fuertes vestigios del colonialismo español, víctima del imperialismo contemporáneo y con importantes recursos naturales en las provincias en donde se encuentran 18 pueblos y 14 nacionalidades, incluidos aquellos aislados de manera voluntaria 5 . La declaración, por un lado tematiza la caducidad de la mirada herderiana sobre las culturas vistas como islas separadas, cerradas y sólidas que, en teoría, se fortalecían de manera independiente hacia dentro pero se diferenciaban del otro; por otro lado, primordialmente responde a una declaración política de rechazo a las concepciones históricas heredadas de los Estados-nación homogenizantes en América Latina del siglo XIX (Walsh, 2009: 65) y que acabaron por ser instrumentos que reforzaron la colonialidad del poder y del saber para, por el contrario, dar paso a un modelo fundado en sociedades interculturales que reconoce como sujetos colectivos distintos a las varias nacionalidades y pueblos que conviven en el territorio ${ }^{6}$, a las que por tanto se corresponda un Estado de nuevo tipo, incluyente, plural, abierto, participativo horizontal que garantice autonomía y supervivencia a estas identidades colectivas y haga frente la discriminación a que son víctimas, labor que no ha podido asumirse eficazmente desde los derechos individuales (De Sousa Santos, 2010: 81-84).

Más adelante, el mismo texto constitucional plantea la manera en la que pretende desarrollar esa declaración. Por ejemplo, el artículo 57 trata sobre

3 Entró en vigencia a través de su publicación en el Registro Oficial número 449 del 20 de octubre de 2008.

4 Artículo 1 de la Constitución de la República del Ecuador.

5 Según el mapa petrolero del Ecuador (2017), los bloques petroleros se encuentran ubicados principalmente en la región amazónica y en la provincia del Guayas. En esa misma región hay presencia de las nacionalidades Ál Cofán, Secoya, Siona, Huaorani, Shiwiar, Zápara, Achuar, Shuar, Kichwa de la Amazonía y los pueblos en aislamiento voluntario Tagaeri, Taromenane y Oñamanane (SIISE, 2017). 6 Achuar, A’l Cofán, Huaorani, Kichwa Amazonía, Secoya, Shiwiar, Shuar, Siona, Zápara, Awá, Chachi, Epera, Tsachila, Kichwa andina y los siguientes pueblos: Karanki, Natabuela, Otavalo, Kayambi, Kitukara, Panzaleo, Salasaka, Kichwa Tungurahua, Chibuleo, Puruhá Waranka, Kañari, Saraguro, Kisapincha, Manta - Huancavilca -Puña y los pueblos en aislamiento voluntario Tagaeri, Taromenane y Oñamenane (SIISE, 2017). 
los derechos colectivos de las comunas, comunidades, pueblos y nacionalidades indígenas, dotando, a estas formas organizativas, un reconocimiento como sujetos de derechos, que por la forma en la que se desenvuelve su vida social, sus vivencias colectivas no contemplan una mediación de miembros individuales del grupo, ni una existencia separada de la comunidad (Sánchez, 2000: 63). Este artículo cumple con las obligaciones mínimas que impone a los Estados el Convenio sobre pueblos indígenas y tribales No. 169 de la Organización Internacional del Trabajo que entró en vigor el 5 de septiembre de 1991, y del cual es signatario el Ecuador ${ }^{7}$, así como el contenido de la Declaración de las Naciones Unidas sobre los Derechos de los Pueblos Indígenas ${ }^{8}$. Además, reconoce y desarrolla derechos para los pueblos que se han mantenido voluntariamente sin contacto con el resto de la sociedad, relacionados con esa situación, sus tierras y la actividad extractivista. Destacan para fines de este trabajo los últimos dos párrafos del artículo mencionado, los que a continuación cito:

Los territorios de los pueblos en aislamiento voluntario son de posesión ancestral irreductible e intangible, y en ellos estará vedada todo tipo de actividad extractiva. El Estado adoptará medidas para garantizar sus vidas, hacer respetar su autodeterminación y voluntad de permanecer en aislamiento, y precautelar la observancia de sus derechos. La violación de estos derechos constituirá delito de etnocidio, que será tipificado por la ley.

El Estado garantizará la aplicación de estos derechos colectivos sin discriminación alguna, en condiciones de igualdad y equidad entre mujeres y hombres.

Sobresalen algunos elementos en el texto transcrito. Primero, el reconocimiento implícito a nivel constitucional de la existencia de pueblos en el territorio ecuatoriano que por decisión propia se mantienen sin contacto con el resto de la sociedad. Segundo, el reconocimiento expreso de la existencia de tierras de posesión ancestral de estos pueblos. Tercero, la prohibición expresa de que la delimitación de esos territorios pueda ser reducida o intervenida por algún agente. Cuarto, la prohibición expresa de realizar actividades extractivistas de los recursos existentes en esos territorios que, en relación con la condición de territorio intangible, incluiría todas las fases de dichas actividades, tales como la prospección, exploración y explotación de los recursos renovables y no renovables. Quinto, la obligación estatal de establecer medidas para mantener el aislamiento voluntario y asegurar las vidas de los individuos de esos pueblos.

7 El Convenio fue suscrito por el Ecuador en junio de 1989 durante la 76 Conferencia Internacional del Trabajo y ratificado mediante Decreto Ejecutivo No 1387 de 6 de mayo de 1998.

8 Aprobada por la Asamblea General de las Naciones Unidas el 13 de septiembre de 2007. 
Sexto, la obligación de legislar tipificando la violación de estos derechos como delito de etnocidio. Séptimo, la obligación estatal de garantizar los derechos consagrados en este artículo con un enfoque de género y sin discriminación alguna.

La problemática en torno a los pueblos indígenas, particularmente los que por decisión voluntaria se mantienen sin contacto con el resto de la sociedad tiene una larga historia. No es objetivo de este artículo tratarla, sin embargo cabe mencionar que el artículo recibe la influencia de las conveniones y tratados internacionales, pero sobre todo de la historia de abuso, desplazamiento y apropiación del territorio de estos pueblos.

La literatura cuenta el mundo, recoge los discursos que ya existen y circulan en la sociedad, su mérito está en fortalecer y facilitar esta circulación simbólica. Así textos como Cumandá de Juan León Mera (1891) que narran sucesos en épocas de evangelización católica de los amazónicos del Ecuador en el siglo XIX o las narraciones del investigador Miguel Ángel Cabodevilla (2005 y 2006) sobre la historia de los pueblos en aislamiento voluntario, además de las demandas y acciones de los movimientos indígenas del Ecuador, junto a otros factores políticos podrían haber influido en la introducción del artículo 57 en el más alto nivel del ordenamiento jurídico del país.

Al revisar el Convenio No. 169 de la OIT y la Declaración de las Naciones Unidas sobre los Derechos de los Pueblos Indígenas se observa que estos no contemplan declaración u obligación expresa para los Estados en relación a los derechos de los pueblos no contactados, aunque existen algunos artículos de este último instrumento que podrían interpretarse como un marco de referencia para el desarrollo de derechos específicos para este grupo 9 (Oficina del Alto Comisionado de las Naciones Unidas para los Derechos Humanos y los Pueblos Indígenas aislados y en contacto inicial, 2006: 308-310). Es decir, el Ecuador no tenía ninguna obligación internacional de desarrollar derechos específicos para los pueblos no contactados que no sean aquellos establecidos por los instrumentos internacionales para los pueblos indígenas en general.

No obstante, la ampliación de los derechos de estos grupos en particular responde, por un lado a la intención de resarcir los perjuicios sufridos por estos pueblos a causa de su división, la violencia y la reducción de sus tierras provocada por la evangelización católica, el extraccionismo y el abandono y olvido del Estado; y por otro lado, sellar toda nueva posibilidad de que se produzcan sucesos similares en el futuro, principalmente, imponiendo una limitación al Estado de realizar o permitir extracción de recursos naturales de los territorios de dichos pueblos.

En la obra literaria de Juan León Mera (1891) denominada Cumandá, novela del romanticismo y costumbrismo ecuatoriano que relata una trágica 
historia de amor entre un criollo y una india amazónica, se identifican pasajes que muestran como la evangelización católica dividió a los pueblos y nacionalidades que habitaban el territorio amazónico del Ecuador en el siglo XIX, así:

A poco empezaron a llegar y detenerse, frente a Andoas, canoas y balsas henchidas de familias záparas, que moraban a las márgenes del Copataza y del Pindo o a las faldas del Abitahua. Hasta los salvajes del Rotuno, el Curaray y el Veleno, por no atravesar lo intrincado de las selvas por largo trecho, habían preferido trasmontar la cordillera de Conambo para abandonarse a la suave corriente del Bobonaza, y unidos luego a sus aliados los habitantes de Canelos, Pacayacu y Zarayacu, descender al lago de la cita. Muchos de aquellos eran cristianos, mas habían obtenido licencia de sus misioneros para acceder a la invitación de los jívaros paloras. A tal condescendencia contribuyó mucho la terrible idea que, así los religiosos como los indios conversos, tenían de aquellos bárbaros. Por acatamiento al curaca de éstos, habían convenido todos en esperarlos en el puerto de Antoas. Era digna de verse la ancha desembocadura del Bobonaza cuando vomitaba sobre el Pastaza la multitud de barquillas rústicamente empavesadas (Mera, 1891:36).

Este pasaje describe como las comunidades que habían sido evangelizados estaban supeditadas a las autorizaciones de los representates de la iglesia católica para mantener relaciones con otras comunidades no evangelizadas.

En el mismo texto, también se relata la constante lucha de sus habitantes originarios por mantener sus costumbres y territorio.

La guerra se hace entre los indios frecuentemente por medio de sorpresas, y sus ataques nocturnos son terribles. Caminan largas leguas por tierra o por agua con tales precauciones que no se les siente, y muchas veces se arrastran como culebras considerables trechos, o van sepultados en las ondas hasta el cuello para aproximarse, sin ser vistos, a la población que se proponen asaltar. La muerte y el exterminio que llevan consigo son infalibles; el silencio profundo de que van rodeados, es el espantoso precursor del que reinará después en el lugar que talarán y cubrirán de cenizas [...] (Mera, 1891: 76).

Dentro de la obra, este pasaje se enmarca en la narración de las batallas entre las comunidades que se resistían a las influencias de la evangelización o al relacionamiento con los colonos.

El autor Miguel Cabodevilla (2006: 118 -131) señala que gran parte de los indígenas de la amazonía ecuatoriana se mantuvieron sin contacto con el resto 
del Ecuador hasta el año 1958, el Estado no mantenía ninguna preocupación por este grupo de personas que habitaban en el territorio nacional, sino hasta que se descubrió la existencia de petroleo en dichas zonas; por esta razón inició la ocupación de los territorios tradicionalmente habitados por la nacionalidad Huaorani con una extensión de 2’000.000 de hectáreas y luego en 1969 una misión evangélica trabajó en la zona para lograr una reducción del grupo Huaorani a un territorio de 16 mil hectáreas. Parte de estos indígenas decidió no continuar con el contacto y mantener su territorio contra la ocupación de las empresas petroleras y otros grupos. Desde estos sucesos ocurridos en la década del 60 del siglo XX, existió un olvido del Estado por estos grupos; casi 30 años más tarde, en 1999 se expidió el Decreto Ejecutivo No. 552 para la creación de la Zona Intangible en el Parque Nacional Yasuní con el fin de proteger a los pueblos ocultos Tagaeri/Taromenani. El autor además señala que a lo largo de esos años sucedieron una serie de actos violentos que culminaron en muerte producto de enfrentamientos entre empleados de las empresas petroleras, madereros ilegales o miembros contactados de la nacionalidad huaorani con los pueblos no contactados.

La problemática descrita en la obra literaria Cumandá y en los estudios realizados por investigadores como Cabodevilla tiene una respuesta en el artítulo 57 de la Constitución, al buscar resarcimiento y garantías para el futuro en el marco del reconocimiento de las diferencias en la igualdad.

Por otro lado, el texto de los últimos dos párrafos del artículo 57 de la Constitución de la República del Ecuador ha sido objeto de una transmutación en el mundo del arte. Los artistas ecuatorianos Alex Alvear y Miguel Alvear (2013) crearon una nueva obra multimedia que incorpora el texto de estos párrafos a una composición musical en la que se muestra la intromisión de las prácticas extractivistas en la época del boom petrolero, imágenes reales de la vida de los pueblos amazónicos y los cambios de sus costumbre y creencias por la alienación a los hábitos occidentales. Esta obra se ha puesto a disposición en un canal público de Youtube $^{10}$ con lo cual el potencial de irradiación se incrementa, pues no está encerrado en los espacios tradicionales de exposiciones artísticas o conciertos.

Lo descrito en esta parte muestra al menos dos de las posibles interacciones entre literatura y derecho. La primera en la que la literatura a través de las grandes obras puede influir en la creación de Derecho, en este caso a través de normas emanadas por el legislador. En el caso descrito, la obra Cumandá de 1891 considerada una novela clásica de la literatura ecuatoriana leída por muchos años como parte del currículo escolar, debió tener pocas oportunidades de influir en la creación del artículo 57 de la Constitución de 2008 por la distancia temporal que mantienen, claramente no logró ninguna influencia 
entre la fecha de su publicación a finales del siglo XIX hasta finales del siglo $\mathrm{XX}$, tiempo durante el cual no existió declaración o acción estatal a favor de reconocer la existencia de los pueblos no contactados ni de garantizar los derechos de los pueblos indígenas amazónicos, lo cual se aproxima al resultado obtenido en el estudio de Delgado y Stefanic (1991) arriba mencionado; es decir mientras existió un abismo entre las dos culturas, la literatura no sensibilizó ni empatizó, -en este caso a los políticos- para tomar decisiones legislativas a favor de los pueblos indígenas y, en particular, de los no contactados, lo que sí es posible, es que haya incidido en la idea que durante muchos años tuvieron los individuos con acceso a educación en las urbes ecuatorianas sobre los habitantes de la selva amazónica, durante buena parte del siglo XX, seguramente, muchos de ellos, políticos, jueces y abogados.

Los textos de Cabodevilla podrían tener mayor proximidad e influencia en el artículo. En el Acta de la sesión número 77 de la Asamblea Nacional Constituyente en la que se realizó el primer debate de la propuesta del texto constitucional sobre los derechos colectivos, consta la fundamentación del informe de mayoría propuesto por la mesa correspondiente, que señala:

Los debates fueron alimentados con los criterios presentados en la Mesa por el Relator Especial de las Naciones Unidas para los Pueblos Indígenas, quien vino acompañado de la máxima dirigencia de la CONAIE $^{11}$. A más de ello se ha contado con la presencia de otras expertas internacionales de países como Colombia, donde de igual forma se han reconocido constitucionalmente los derechos colectivos y su aplicación práctica ya ha presentado dificultades. Finalmente, también fueron tomados en cuenta los aportes de Boaventura de Sousa do Santos, reconocido pensador contemporáneo, defensor a ultranza de la plurinacionalidad quien manifestó el riesgo que implica mantener postrados a los pueblos indígenas frente a las aspiraciones neo colonialistas de los países que, a toda costa, buscan el control y la explotación de los recursos de sus territorios [...] (Asamblea Constituyente del Ecuador: 4-5).

El texto transcrito es la única declaración explícita sobre las influencias recibidas para la redacción de los textos constitucionales sobre los derechos colectivos de los pueblos y nacionalidades, sin que eso implique que los asambleistas no hayan sido individualmente influenciados por la literatura a través de los pasajes encontrados en la obra escrita Cumandá o sino las representaciones derivadas de este imaginario de explotación encontradas en la literatura oral. Se puede en todo caso solo ejemplificar la capacidad de influencia 
directa en la creación normativa al revisitar la intervención realizada por la Asambleista Aminta Buenaño (2008) quien, para proponer el reconocimiento en la Constitución de los pueblos montubios señaló: “Uno de los grandes valores de la literatura es que testimonia la realidad, que se convierte en un documento social que habla sobre la vida de los pueblos" (Asamblea Constituyente del Ecuador, 2008) y más adelante se refiere a las obras de varios escritores ecuatorianos como José de la Cuadra con su obra Los Sangurimas, Luis A. Martínez con su obra A la Costa, Enrique Gil Gilbert, Joaquín Gallegos Lara y Demetrio Aguilera Malta con la obra Los que se van, que describen la vida y penas del pueblo campesino del litoral ecuatoriano conocidos como el pueblo montubio.

\section{La creación audiovisual de los hermanos Alvear: Puente entre el Arte el Derecho y la Sociedad}

La segunda interacción, en la que el Derecho es la Literatura -arte o cultura popular-, se podría considerar que en ese sentido se entiende la obra artística de Alex Alvear y Miguel Alvear. La letra de la canción denominada Artículo 57 corresponde en su lírica exactamente a los últimos dos párrafos del artículo 57 de la Constitución de la República. En confluencia con la música de género fusión entre rock, reggae, jazz y blues forma una obra nueva, con un tono de advertencia, acompañado de un video que constituye una denuncia gráfica de los sucesos relatados por los textos de Juan León Mera y Miguel Cabodevilla, así como, por las manifestaciones sociales por los derechos de los pueblos indígenas.

La función de esta obra, más allá del agrado o desagrado estético, es la de narrar a través del texto del Derecho una aspiración de la sociedad ecuatoriana, dándole un breve contexto que motiva su existencia. Su formato de difusión libre por medio de las tecnologías de la información le da amplias posibilidades de amplificación sin límites geográficos ni de clase.

Esta obra podría ser considerada un ejercicio de traducción o interpretación del Derecho si tomamos los términos en los que Roman Jakobson citado por Aguiar e Silva (2008: 31) describe la tipología para la interpretación de signos verbales, que en su tercer tipo hace referencia a la traducción intersemiótica o transmutación que es una interpretación de signos verbales mediante signos de sistemas de significación no verbales. Es decir, los artistas han realizado su propia comprensión del contenido de los últimos dos incisos del artículo 57 de la Constitución de la República y a través de la combinación de la música, el texto del artículo y las imágenes del video, interpretan su contenido - fuera del mundo jurídico. La obra podría constituir un mediador para la difusión, comprensión y contextualización del Derecho que a su vez será interpretada por quienes la observen (Bruder, 2000: 356-357). 
Es claro que la interpretación a la que se hace referencia no es aquella del mundo jurídico que le corresponde a los jueces o los legisladores para crear Derecho. No obstante, sí está relacionada con la interpretación como actividad humana que deconstruye y se apoya en elementos fuera del texto para dar sentido y comprender lo que el lenguaje escrito o hablado no alcanza a mostrar. Además, este ejercicio podría o intenta enmarcarse en las intersecciones entre el Derecho y la cultura, en el doble sentido de producto y productor de cultura hegemónica (Elholm Thomas, 2012: 8) que específicamente en el caso de la cultura popular son cada vez más frecuentes. La letra de la canción es derecho y su formato audiovisual y su difusión le dan oportunidad a su narrativa de amplificar el poder moldeador de cultura en torno al Derecho. La cantidad de personas que acceden a la lectura directa de una norma jurídica generalmente es reducida, se concentra en los operadores jurídicos, políticos, estudiantes de Derecho, académicos especializados en el área o personas directamente interesadas en un aspecto jurídico que les atañe a una situación particular propia; sin embargo, esta obra permite ampliar ese espectro, puesto que cualquier persona que asista por interés o casualidad a un concierto en el que se interprete la canción Artículo 57 o acceder a ella por otros medios, principalmente a través del internet, conocerá el fragmento del texto de los derechos colectivos de los pueblos indígenas en aislamiento voluntario, que quizás no sabía que existía o peor aún, podría ser que tampoco tenía idea sobre la existencia de grupos indígenas en aislamiento voluntario, los contexto de esa situación, su historia conocida y las amenazas que los acechan.

Aguiar e Silva (2008: 120-132) aborda desde la mirada de Sherwin los riesgos de la sociedad posmoderna y de las deformaciones del derecho a través de la cultura popular, así como señala las oportunidades de una formación jurídica más humanista a través de la aproximación al tema para el desarrollo del pensamiento crítico. Así, cita a Judith Hagley, quien señaló: "law should go pop, but not by selling out its very soul" (el Derecho será pop, pero no vendiendo su alma) (Aguiar e Silva, 2008: 128), y se da la pauta para pensar en que, a través de las interacciones de la cultura y derecho, es posible que también se puedan constuir imaginarios colectivos alternativos que no obedezcan únicamente a los valores de mercado de la cultura popular sino que se enfoquen a la educación empática de los ciudadanos sobre los derechos propios y de los demás. Sobre esta base podría decirse que la obra de los Alvear es un intento de infiltración dentro del sistema de la cultura popular, de sus medios masivos y formatos, que busca deshomogenizar los sentidos, usando el derecho para contar las historias alternativas que no se muestran en la cultura hegemónica. Quizás es un intento de hacer en el espacio de los sentidos lo que señalan Hardt y Negri (2000) para la política, al final de la segunda parte de su obra Imperio. 
Por lo tanto, ser republicano en este momento significa, en primer lugar, pelear desde adentro y construir contra el Imperio, en sus terrenos híbridos y modulantes. Y aquí debemos agregar contra todos los moralismos y las posturas del resentimiento y la nostalgia, que estos nuevos terrenos imperiales proveen mayores posibilidades de creación y liberación. La multitud, con su voluntad de oponerse y su deseo de liberación, deberá empujar a través del imperio para salir por el otro lado (Hardt y Negri, 2000: 119).

Las interacciones entre el derecho y la literatura, son parte de las interacciones del derecho y la cultura, el ejemplo tratado intenta mostrar que cada vez las fronteras disciplinares se vuelven más difusas y que los elementos y ángulos para los estudios interdisciplinares que involucran al Derecho se incrementan y en ese marco se abren oportunidades para recuperar los fines humanistas del Derecho.

\section{Referências bibliográficas}

AGUIAR E SILVA, Joana (2008), Para uma teoría hermenéutica da justiça. Repercussões jusliterárias no eixo problematico das fontes e da interpretacão jurídicas, Braga, Universidad de Minho.

ALCHOURRÓN, Carlos \& Bulygin, Eugenio (1987), Introducción a la metodología de las ciencias jurídicas y sociales, Buenos Aires, Astrea.

ALVEAR, Alex \& ALVEAR, Miguel (2013), Artículo 57 [Online], disponible en: https://www. youtube.com/watch? $=3 \mathrm{VxWP} 1 \mathrm{hGyjg}$ [consultado en: 5-12-17].

ASAMBLEA CONSTITUYENTE DEL ECUADOR (s.f.), Acta 077, Debates de la Asamblea Constituyente del Ecuador, Montecristi, Asamblea Constituyente.

ASIMOW, Michael, BROWN, Kathryn, \& Ray, David (2014), Law and Popular Culture: International Perspectives, New Castle, Cambridge Scholars Publishing.

BOTERO, Andrés (2008), "Derecho y Literatura: un nuevo modelo para armar, Instrucciones de uso", The Cardozo Institute [Online], disponible en: http://www.jus.unitn.it/cardozo/ Review/2008/Botero.pdf [consultado en: 10-12-17].

BURKE, Edmund (2015), Uma Investigação Filosófica Acerca da Origem das Nossas Ideias do Sublime e do Belo, Lisboa, Ediçoes 70.

BRUDER, Kurt (2000), “Interactive Art Interpretation: How Viewers Make Sense of Paintings in Conversation", Symbolic Interaction, (23), 337-358.

CABODEVILLA, Miguel (2005), Pueblos no contactados ante el reto de los derechos humanos, Quito, Centro de Propaganda Difusora Bíblica Franciscana.

CABODEVILlA, Miguel (2006), "Pueblos ocultos", Pueblos indígenas en aislamiento voluntario y contacto inicial en la Amazonía y el Gran Chaco, 118-131.

DELGADO, Richard \& Stefancic, Jean (1991), "Norms and Narratives: Can Judges Avoid Serious Moral Error", Texas Law Review, 1929-1984.

DE SOUSA SANTOS, Boaventura (2010), Refundación del Estado en América Latina: perspectivas desde una epistemología del Sur, Lima, Plural Editores.

ELHOLM, Thomas \& PORSDAM, Helle (2012), Dialogues on Justice: European Perspectives on Law and Humanities, Berlín/Boston, Gruyter. 
HARDT, Michael. \& NEGRI, Antonio (2000), Imperio, Cambridge, Harvard University Press. MERA, Juán León (1891), Cumandá, Madrid, Librería de Fernando Fé.

OFICINA DEL ALTO COMISIONADO DE LAS NACIONES UNIDAS PARA LOS DERECHOS HUMANOS Y LOS PUEBLOS INDÍGENAS AISLADOS Y EN CONTACTO INICIAL (2006), "Oficina del Alto Comisionado de las Naciones Unidas para los Derechos Humanos y los Pueblos Indígenas aislados y en contacto inicial”, en Pueblos Indígenas en Aislamiento Voluntario y Contacto Inicial en la Amazonía y el Gran Chaco, 302, 311.

PORSDAM, Helle (2007), “A review of A Critical Introduction to Law and Literature by Kieran Dolin", Law and Humanities, 131-137.

ROSAS, Joao (2017), Concepções da Justiça, Lisboa, Ediçoes 70.

SÁNCHEZ, Esther (2000), "Reflexiones antropológicas en torno a la justicia y la jurisdicción especial indígena en una nación multicultural y multiétnica", en Fernando García Coord., Las sociedades interculturales um desafio para el siglo XXI, Quito, FLACSO.

SECRETARÍA DE HIDROCARBUROS (2017), Mapa petrolero del Ecuador, [Online], disponible en: http://www.secretariahidrocarburos.gob.ec/mapa-de-bloques-petroleros/ [consultado en: 17-12-18].

SIISE (2017), Sistema Integrado de Indicadores Sociales del Ecuador [Online], disponible en: http://www.siise.gob.ec/siiseweb/PageWebs/Marco\%20Conceptual/macsdp_introd.htm [consultado en: 17-12-18].

WALSH, Catherine (2009), Interculturalidad, Estado, Sociedad, Luchas (De) Coloniales de Nuestra Época, Quito, Universidad Andina Simón Bolívar-Abya Yala. 